\title{
Enablers and Barriers for Mobile Commerce and Banking Services Among the Elderly in Developing Countries: A Systematic Review
}

\author{
Nkosikhona Theoren Msweli ${ }^{(\bowtie)}$ (D) and Tendani Mawela (D) \\ Department of Informatics, University of Pretoria, Pretoria 0002, South Africa \\ nkosikhona.msweli@gmail.com, tendani.mawela@up.ac.za
}

\begin{abstract}
The rollout of mobile banking has taken over the traditional banking space in both developed and developing countries. Banking institutions are continuously seeking innovative digital solutions to stay ahead of competitors and be the first preference to consumers. Scholars have also shown some interest in investigating mobile commerce and banking implementation and adoption. However, research studies focusing on the elderly and mobile banking are scant. This paper seeks to understand the current state of knowledge regarding the enablers and barriers of mobile banking and commerce among the elderly by providing a systematic review of the existing literature on the phenomenon.

The literature review showed that there is minimal research to date that has been conducted on this topic of interest. Consequently, issues of investigating enablers and barriers of mobile banking among the elderly have been fairly neglected. The main barriers noted in the literature include: security concerns, trust and privacy, a lack of personalization and limited technical knowledge of the elderly. Significant enablers that may be considered are: perceived ease of use of mobile banking applications, perceived value, convenience and consumer attitudes. Future directions for research and practice on mobile banking for the elderly are suggested.
\end{abstract}

Keywords: Elderly $\cdot$ Mobile commerce $\cdot$ Mobile banking $\cdot$ M-banking · Cellphone banking $\cdot$ Developing countries

\section{Introduction}

The growth in the proliferation of smartphones and implementation of fast wireless network connections such as $4 \mathrm{G}$ and now $5 \mathrm{G}$, means that the mobile market can have a variety of offerings such as mobile banking worldwide without any space or time limitations. Mobile commerce and as such mobile banking removes spatial and temporal limitations, enabling customers to conduct ubiquitous payments [1] and to shop globally. The driver behind mobile electronic offerings such as mobile banking and commerce was to enable the suppliers to reach a wider audience at an affordable and convenient level, while increasing their revenue at the same time. The elderly population, in particular, may gain powerful assistance through having mobile applications and $\mathrm{m}$-commerce on hand for their daily requirements [2]. 
The banking industry is among the early adopters of these mobile technological innovations [3]. However, the use of m-banking is still lower than anticipated, especially among the elderly population group. The youth are reported to be leading in technology usage whereas the elderly are reportedly lagging. It is important that various customer groups are afforded an equal opportunity to benefit from online public and private services [4] especially in the digital era. Research has reported the exclusion of the elderly in as far as the deployment of Information and Communication Technology (ICT) $[4,5]$. Unfortunately, the case of the elderly's digital inclusion seems to receive little attention. Digital barriers can be a factor behind the exclusion of the elderly [6]. The digital inclusion of the elderly could positively impact on the social and economic welfare for this segment of the population subsequently improving their quality of life [7]. It is worth mentioning that the current elderly people are not digital natives. Thus, if the users have a limited understanding or familiarity of any given technology, it is likely that they will not use the products offered through that technology [8].

The elderly represent a significant business opportunity for online marketers [9], and it may be a missed opportunity if the elderly's needs are not catered for in the technology rollout. Technology continuously changes and the elderly lack educational opportunities to keep up with it [10]. Some authors indicate that it is not always clear whether the elderly will participate actively on the online and mobile commerce solutions [7]. Iyer and Eastman [9] found that most of the elderly have used the internet before, but the study further revealed that only $35 \%$ used the internet for m-commerce.

The objective of this research study was to understand how mobile banking and commerce has been investigated in the context of the elderly in developing countries in order to identify existing enablers and barriers. The research question driving the study was: What are the enablers and barriers for mobile commerce and banking among the elderly in developing countries?

The remainder of the paper is structured as follows: The next section contains the background and motivating information about the elderly, mobile banking and developing countries. Then the research methodology which details how papers were identified, selected and analysed. Finally, the discussion of findings, conclusions and recommendations are presented.

\section{Background and Motivation}

\subsection{Mobile Commerce and Banking}

There is no agreed upon definition that has been put forward to define mobile banking in the extant literature. Nonetheless, Shaikh and Karjaluoto [11] argue that accessing banking or financial services from a laptop should not be considered m-banking, since the user interface is similar to that of desktop PCs. According to Touchaie and Hashim [12], m-banking is the act of conducting monetary transactions in a mobile environment, using mobile or wireless network and mobile devices such as smartphones and tablets. Mobile payments are considered a subset of mobile banking. Houghton [13] considered paying for your car fuel or parkade tickets through vending machine via smartphone's credits as a payment method to be an example of m-commerce. Some 
authors refer to it as cellphone banking. Mlitwa and Tshetsha [14] described it as a convenient banking channel to manage finances using a mobile phone. According to Al-jabri and Sohail [15], mobile banking services allow customers to take full advantage of the latest technology which enables them to: check account details; view a mini-statement; transfer funds; pay credit cards and loan installments and place remittances to beneficiaries in local banks or abroad, to highlight a few.

Mobile banking technology offers a variety of possible products and services that banks can avail to consumers [16]. Among other services, M-banking systems offer a variety of financial features such as micropayments to merchants, bill-payments to utilities, person to person (P2P) transfers, business to business (B2B) transfers, business to person (B2P) transfers and long-distance remittances [17]. Khan, Varshney and Qadeer [18] suggested that it is mobile commerce (m-commerce), they continued to define it as buying and selling of goods and services using wireless technology. Khan, Varshney and Qadeer further identified mobile banking as one of the products and services available in the mobile commerce (m-commerce). Thus, mobile financial services fall under this umbrella such as mobile personal banking and payments [19]. Mobile banking is currently available via SMS technology and WAP-enabled mobile phones [20, 21]. The capability to use banking and other m-commerce applications with such a small device effectively with good interaction is a critical success factors of mobile buying and selling [22]. Mobility is often a challenge for a number of elderly individuals. Thus mobile shopping and banking can be beneficial to this cohort who would then essentially not have to leave their homes or comfort to perform financial transactions [1].

Mobile banking seems to offer several possibilities to either increase revenues or reduce costs [16], however the usage rate remains low [20], except in developed countries where it is heavily adopted [21]. For South Africa and other developing countries, mobile banking serves as a vital interface between consumers and the banks by permitting money transfer, saving and investment opportunities [23]. Mobile banking is further described as a contributor towards financial inclusion for such countries with a tele-density of $70 \%$ [24]. The provision of mobile banking is increasing but awareness of the service by banking consumers and the convenience that it entails requires more effort on the part of banking services providers [25].

M-banking dates back to the late 1990s where it was first launched in Germany [11]. Primary research on mobile banking was conducted in the early 2000s [25]. The adoption of mobile banking and related services in developing economies has been studied [19] over the past years in countries such as: South Africa (MTN money, Wizzit), Kenya (mPESA), India (Eko) and in continents such as Asia (SmartMoney and G-Cash) [26-30]. However, studies about the elderly behaviour on mobile banking and commerce are rare [2, 31], a few studies have examined ease of use and extrinsic and intrinsic motivations for the elderly's usage of mobile applications [32]. Convenience and efficiency are top mobile banking benefits [26] cited in the literature.

\subsection{The Elderly Population}

Most scholars define the elderly as individuals aged 50 and above [12, 33]. Applying policies and regulations from different countries, this definition is argued. Similarly, in 
natural science or clinical psychology various issues are considered. In addition, the needs of the elderly are linked to the age-related changes that they face [34]. Mallenius, Rossi and Tuunainen [35] argue that, ageing differs with individuals, while there are energetic and sharp elderly aged over 80 , there are 60-year-old people, who struggle with their daily routine.

People are living longer than at any other time recorded in history [36]. The elderly population globally is growing dramatically [33, 37]. In this digital economy the elderly's needs and concerns as technology users differ from other groups due to natural changes associated with aging [38]. Considering the available medicines and technologies, many of today's elderly people desire an active retirement and prefer learning new skills [9] that they can use in this digital era. Furthermore, the elderly are using digital technologies for work and entertainment [38].

In the commercial market, to understand the elderly consumer behavior, it is important to understand who elderly people are [12] and their attitudes and behavior towards technology [36]. It is worth mentioning that the relationship with technology might be different for older adults compared to young people, since the elderly did not grow up with technology and currently have less contact with these innovations [39]. However, the literature reports that in China the elderly had positive attitudes and beliefs concerning information technology [36].

Technology has been reported to have an ability to simplify the lives of elderly individuals. In the view of Jayachandran [40], the elderly have developed a technophobia which may prompt them to stay away from any technology. Although the elderly group may believe in traditional resources, having digital skills to easily access available digital technologies may allow people to engage with and participate in almost every level of public life, from social networking to e-Government [41]. The elderly can have a hard time assimilating digital technologies like mobile banking. As such it is important that mobile service providers consider how to support the elderly integrate into modern societies [4].

\subsection{Developing Countries}

Mobile commerce has presented several benefits to many individuals and organisations in developing countries [42]. However, mobile banking in developing countries is still constrained, with only few individuals who can access it, due to strict banking regulations and a high number of unbanked individuals [43-45]. Developing countries, heavily dominated by low-income individuals [30], are faced with a variety of challenges and limitations such as access to quality health services and education, and they are lagging in technology implementation. Such countries with a high rate of unbanked citizens, have relied on low-cost banking solutions such as MPesa [26] to accommodate the unbanked citizens.

Previous research on developing countries has indicated that financial literacy is an important factor for effective financial decision making which in turn influences citizens' financial behavior [46]. In many cases, individuals with low financial literacy will ignore banking applications and the benefits they may bring. Examining issues such as trust, may increase the use of mobile technologies in developing countries [47]. Considering the disadvantaged background, change in political structures for these 
countries does not culminate in economic power or wealth [23]. Also, poverty is evident in such countries and the digital technologies and other (ICT) infrastructure are still under development [13]. Thus, low-cost banking may benefit citizens in these countries. Some researchers have indicated that mobile technology can reduce the effect of poverty [47]. However, it is unclear if people in low-income countries will adopt mobile banking technology [26], since the appetite for banking services in these countries is not high. According to Thakur [50], Dass and Pal [48], as well as Sharma [49], the demand for m-banking can be improved by increasing the demand for banking and financial services through increased awareness about various available products.

\section{Research Method}

The study adopted a systematic literature review (SLR) approach which provides a transparent research process to study patterns and evidence from prior research studies [50]. The approach used is based on the guidelines proposed by [51]. The procedure undertaken was as follows: Define search terms; Select sources (digital libraries) on which to perform the search; Application of search terms on sources; and Selection of primary studies by application of inclusion and exclusion criteria on search results.

The aim of a SLR is to identify all research studies, those that are published and unpublished that address a specific question [50]. Like any other research approach, the SLR has benefits and limitations. The major advantage of this method is that it provides information about the effects of some phenomenon across different environments, and also maintaining the ability to establish whether the study is robust and transferable [51]. Even though the SLR approach requires more effort compared to other approaches [51], it matched the requirement of the study which was to understand what is known in the scholarly literature about the barriers and enablers for the elderly regarding mobile commerce and banking. The approach adopted in this study, looked at the published papers in the last 10 years (2009-2019), focusing on the association between mobile banking, m-commerce and the elderly in developing countries. The following search terms and combinations were used in this systematic review: (Mobile banking OR m-banking OR mbanking OR Mobile commerce OR Mcommerce OR mcommerce) AND (Elderly OR Senior citizen OR Seniors OR Older adults OR Older people) AND (Developing Countries). The electronic libraries did not yield much data on the phenomena of interest. Mobile banking is still emerging in several countries [33], thus few studies were returned, and most did not contain the search text. The articles that did not contain the search text were omitted immediately. Due to a minimal number of relevant research studies returned, it was decided that research articles should not be limited only to developing countries but rather focus on elderly and mobile banking and m-commerce in general.

To minimize bias in a review, inclusion and exclusion selection criteria needs to be clearly defined [50]. It happens in some cases that the selected studies are irrelevant to the research question and objectives. Having selection criteria eliminate such issues. Publications that met any of the following criteria were selected as primary studies: A research study that primarily focuses on mobile banking or m-commerce and the elderly; A research study that focuses on mobile payments and the elderly, and Studies 
published in English between year 2009 and 2019, the intention was to focus on research development in the past 10 years. Publications that met any of the following criteria were excluded from the review: Mobile banking or mobile commerce studies that do not focus on the elderly; Studies published before 2009; and Studies not published in English.

Figure 1 highlights the process followed to select the papers. The studies were reviewed to extract the drivers and barriers towards mobile banking and commerce. The search resulted in 11 relevant publications, of which four were published in different journals and some published as part of conference proceedings and student dissertations. Based on the search results, only four of these research studies were conducted in the developing countries. The majority of the papers investigated adoption using a quantitative approach. The searches were conducted on ACM Digital Library, IEEE Xplore Digital Library, Science Direct, ISI Web of Knowledge and Google Scholar. Due to scarcity of research papers focusing on this context, the search was extended to the top eight IS Journals as identified by the Association for Information Systems (AIS). After reviewing the eight IS journals, there were no new articles identified which were relevant to the subject.

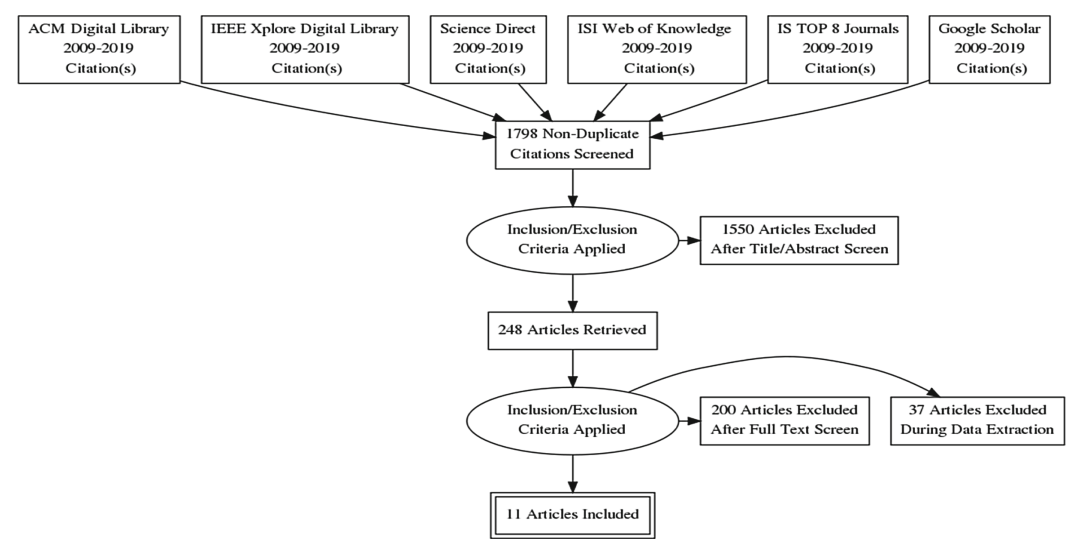

Fig. 1. Articles included in the review

\section{Discussion of the Findings}

Previous studies have reported a lack of interest in this subject area, similarly this study discovered limited literature to examine and extract enablers and barriers for mobile commerce. The research studies included in this review investigated enablers and barriers for mobile commerce and banking among elderly. Most of the studies focus on the factors influencing the use of mobile financial services. It is noted that such technology trends are new, and most elderly consumers still need to be educated or trained on these technologies [52]. Barriers are existing which negatively impact acceptance, adoption and use of mobile commerce among the elderly. Among other things, security and trust are major concerns for this group of individuals [2]. Financial 
institutions must instill trust to reach this audience, despite the existing perceptions of distrust in this sector [47].

Jayachandran [40] studied senior citizens aged 50-plus, to ascertain the type of banking they preferred and reason for their preference. The study was conducted in Kerala, a state located in one of the developing countries in India. The survey method was used in the study, with a sample of 400 banking customers chosen through convenience sampling. The study found that the seniors preferred branch banking since it offers personalized interaction and dealings. This indicated that most elderly have not adopted mobile banking due to lack of personalization or customizing mobile financial applications accommodating their special needs.

Ayaratne, Ryan and Cripps [53] investigated the factors that affect the adoption of M-banking by using a combined Technology Acceptance Model (TAM)-Unified Theory of Acceptance and Use of Technology (UTAUT) framework. Data was collected from 70 elderly people in Australia. Australia is one of the high-income countries. The study was selected due to limited literature available. The results revealed that performance expectancy, facilitating conditions and, perceived ease of use were significant factors that determined the use of mobile banking. Based on the results, the banking application needs to be clear, understandable, user-friendly, and not require a lot of mental effort to learn. The author further noted that the elderly did not find the banking app trustworthy. Due to smaller sample, the study cannot be generalized across the population.

Touchaie and Hashim [12] revealed that there was a negative effect of dispositional resistance to change (DRTC) on mobile banking adoption among elderly. This means there is high resistance to change around this population segment. The data was collected using the survey method in Kuala Lumpur from elderly aged over 50. The participants were non-users of mobile banking. A sample of 384 was obtained and Partial Least Squares Structural Equation Modelling (PLS-SEM) was used to analyze the data. It can be recorded that resistance to change is a barrier towards adoption of mobile banking. Marketing strategies used by online services providers such as $\mathrm{m}$ banking were not appropriate to attract the market segment that is unwilling to use services such as senior market. Thus, understanding factors that negatively impact the adoption of m-banking by a particular market segment may help to develop strategies which assist to overcome the barriers in their adoption.

Choudrie et al. [33] conducted a systematic review of studies on mobile banking, and older adults and on older adults and smartphones. The aim of the paper was to understand and explain the factors that influence the adoption, use and diffusion of mobile banking among older adults. The study found that there are few studies of older adults' relationships with mobile banking and smartphones. The results further revealed that the innovativeness of device and a product or service such as mobile banking needs to be compatible with individuals' lifestyles and also offer support service by way of its novelty. The author noted that, by offering support, the consumer perceived difficulties and complexities are often reduced or eliminated, consequently promoting trust while reducing risks. Focusing on trust, the study also introduced a conceptual framework which can be used for future studies. Lian and Yen [2] studied drivers and barriers affecting older consumers' intention to shop online. The study used UTAUT and innovation resistance theory. By comparing younger consumers with their older 
counterparts, and considering gender, the findings indicate that the major factors driving older adults toward online shopping are performance expectation and social influence which is the same with younger consumers. Their study revealed the following barriers: value, risk, and tradition which is different from younger users.

\subsection{Identified Key Enablers}

Use of technology is not an instant act, especially for non-digital natives. Prior experience with technology may lead to positive acceptance of new digital technologies. Ayaratne, Ryan and Cripps [53] showed that individuals who were familiar with other technology were likely to perceive M-banking as easy to use and useful to their lives, and also confirmed this positive factor by finding user-friendliness as the driver of mobile banking adoption. Organisations need to understand that, to leverage the available opportunities, it is important to tap into the right kind of consumer behavior and attitude [1]. Mobile opportunities should be usable and accessible hence, it is vital that mobile applications are suitable for all types of consumers [4]. Usefulness and attitude are direct factors influencing consumer satisfaction leading to the adoption of mobile technologies [54].

\subsection{Identified Key Barriers}

Even though there are a number of benefits reported on mobile banking and commerce, the barriers from internal and external environment do exist preventing the innovation from reaching its potential. Trust was a commonly cited barrier in the literature. Consumers have different views and attitude regarding mobile technologies which generate a number of issues when it comes to acceptance and adoption. In general factors such as a lack of trust of technology and a lack of technology readiness act as barriers to the adoption of mobile financial services [48]. The digital divide and digital literacy are two areas that also caught the attention of the researchers when considering the elderly as digital immigrants [41]. For instance, operating a small user interface of a mobile device may be difficult for the elderly. Also a mobile application with a complicated menu may be difficult for the elderly to remember [12]. While studies prove that elderly customers who have access to electronic services and products are ready for electronic banking and commerce [3], the opposite is reported for mobile commercial products and services. Among barriers, the elderly reported professionally written instructions for operating devices which they did not understand and also the absence of a person who can teach them as key constraints. Additionally, fear is another reason for not using digital technologies. The elderly are afraid of being lost in smartphone or tablet and that they will not be able to login or sign out of the application [41]. Performing online payment is another issue for the elderly attempting to shop online, many consumers preferred cash on delivery due to trust and security issues [2] and privacy [55]. 


\section{Conclusion and Recommendations}

The findings of this study revealed that the elderly group certainly have unique requirements that need to be communicated to mobile commerce providers and designers in order to cater for this growing segment. Mobile banking is still in the emerging stage in various parts of the world, thus future research should focus on building the body of knowledge around this context. There is a need to conduct research studies that adopt data collection methods that probe for answers, which can deliver rich primary data from the elderly. Additionally, the study found that there is a gap in research focusing on the elderly and mobile banking and commerce, which confirmed the findings of [33]. In the light of this, the opportunity for further studies is identified particularly from the perspective of developing countries. Future research should address this gap by focusing on how the elderly needs can be met in this digital era focusing on digital or technology needs.

M-banking and M-commerce are thriving in the global market based on the research studies and published reports on financial markets. The growing numbers of elderly people globally signifies that there is an opportunity to market directly to this group or develop products customized for this segment. However, to customize services for this segment group, enablers and barriers need to be understood, hence the need for research studies in this area of interest. Even though there are barriers, it can be argued that, with time, the elderly will become more interested in mobile commerce and banking to enhance their quality of life. Banks need to communicate to their consumers the measures they will employ to address the elderly issues and concerns being raised [55]. Thus, ICT practitioners and researchers need to propose age-specific design guidelines for mobile devices and mobile applications [34]. Furthermore, in-house training and usage guidance would prove to be useful to this vulnerable group [40].

\section{References}

1. Motwani, B.: Prediction of intention of senior professionals to prefer mobile banking. FIIB Bus. Rev. 5(4), 51-64 (2016)

2. Lian, J., Yen, D.C.: Computers in human behavior online shopping drivers and barriers for older adults: age and gender differences. Comput. Hum. Behav. 37, 133-143 (2014)

3. Diako, B., Lubbe, S., Klopper, R.: The degree of readiness of South African senior citizens for electronic banking: an exploratory investigation. Altern. J. 5, 255-287 (2012)

4. Ekberg, S.: A study of how Swedish agencies are working with eService accessibility for elderly people (2015)

5. Hur, M.H.: Empowering the elderly population through ICT-based activities: an empirical study of older adults in Korea. Inf. Technol. People 29(2), 318-333 (2015)

6. Ordonez, T.N., Yassuda, S., Cachioni, M.: Elderly online: effects of a digital inclusion program in cognitive performance. Arch. Gerontol. Geriatr. 53(2), 216-219 (2011)

7. Ramón-Jerónimo, M.A., Peral-Peral, B., Arenas-Gaitán, J.: Elderly persons and internet use. Soc. Sci. Comput. Rev. 31(4), 389-403 (2013)

8. Boontarig, W., Chutimaskul, W., Chongsuphajaisiddhi, V., Papasratorn, B.: Factors influencing the Thai elderly intention to use smartphone for e-health services. In: 2012 IEEE Symposium on Humanities, Science and Engineering Research, pp. 479-483 (2012) 
9. Iyer, R., Eastman, J.K.: The elderly and their attitudes toward the internet: the impact on internet use, purchase, and comparison shopping. J. Mark. Theory Pract. 14(1), 57-67 (2014)

10. Pikna, J., Fellnerova, N., Kozubik, M.: Information technology and seniors. In: CBU International Conference on Innovations in Science and Education, pp. 702-708 (2018)

11. Shaikh, A.A., Karjaluoto, H.: Mobile banking adoption: a literature review. Telemat. Inf. 32 (1), 129-142 (2015)

12. Touchaie, S.A., Hashim, N.H.: The influence of dispositional resistance to change on seniors' mobile banking adoption in Malaysia. J. Soft Comput. Decis. Support Syst. 5(6), 1$12(2018)$

13. Alfahl, H., Houghton, L., Sanzogni, L.: Mobile commerce adoption in Saudi organizations: a qualitative study. Int. J. Enterp. Inf. Syst. 13(4), 31-57 (2017)

14. Mlitwa, N., Tshetsha, N.: Adoption of cell-phone banking among low-income communities in rural areas of South Africa. iBusiness 4, 362-370 (2012)

15. Al-jabri, I.M., Sohail, M.S.: Mobile banking adoption: application of diffusion of innovation theory. J. Electron. Commer. Res. 13(4), 379-391 (2012)

16. Ha, K., Canedoli, A., Baur, A.W., Bick, M.: Mobile banking - insights on its increasing relevance and most common drivers of adoption. Electron. Mark. 22(4), 217-227 (2012)

17. Chitungo, S.K., Munongo, S.: Extending the technology acceptance model to mobile banking adoption in rural Zimbabwe. J. Bus. Adm. Educ. 3(1), 51-79 (2013)

18. Khan, D., Varshney, P., Qadeer, M.A.: E-commerce: from shopping carts to credit cards. In: 2011 IEEE 3rd International Conference on Communication Software and Networks, pp. 81-85 (2011)

19. Agwu, E.M., Carter, A.: Mobile phone banking in Nigeria: benefits, problems and prospects. Int. J. Bus. Commer. 3(6), 50-70 (2014)

20. Laukkanen, T., Lauronen, J.: Consumer value creation in mobile banking services. Int. J. Mob. Commun. 3(4), 325-338 (2005)

21. Sripalawat, J., Thongmak, M., Ngramyarn, A.: M-banking in metropolitan Bangkok and a comparison with other countries. J. Comput. Inf. Syst. 51(3), 67-76 (2015)

22. Hussain, A., Abubakar, H.I., Hashim, N.B.: Evaluating mobile banking application : usability dimensions and measurements. In: Proceedings of the 6th international Conference on Information Technology and Multimedia, no. 1, pp. 138-142 (2014)

23. Chigada, J.M., Hirschfelder, B.: Mobile banking in South Africa: a review and directions for future research. SA J. Inf. Manag. 19(1), 1-9 (2017)

24. Behl, A., Singh, M., Venkatesh, V.G.: Enablers and barriers of mobile banking opportunities in rural India: a strategic analysis. Int. J. Bus. Excell. 10(2), 209-239 (2016)

25. Al-jabri, I.M.: The intention to use mobile banking: further evidence from Saudi Arabia. South African J. Bus. Manag. 46(1), 23-34 (2015)

26. Ismail, T., Masinge, K.: Mobile banking: innovation for the poor. African J. Sci. Technol. Innov. Dev. 4(3), 98-127 (2012)

27. Borg, F., Persson, M.: Assessing Factors Influencing the Diffusion of Mobile Banking in South Africa - A case study on the company Wizzit Carried (2010)

28. Ayo, C.K., Adewoye, J.O., Oni, A.A.: Framework for mobile money implementation in Nigeria. J. African Res. Bus. Technol. 2011(1), 1-8 (2011)

29. Firdhous, M.F.M., Karunaratne, P.M.: An ICT enhanced life quality for the elderly in developing countries: analysis study applied to Sri Lanka. J. Health Inform. Dev. Ctries. 5, 47-59 (2011)

30. Medhi, I., Ratan, A., Toyama, K.: Mobile-banking adoption and usage by low-literate, lowincome users in the developing world. In: Aykin, N. (ed.) IDGD 2009. LNCS, vol. 5623, pp. 485-494. Springer, Heidelberg (2009). https://doi.org/10.1007/978-3-642-02767-3_54 
31. Zhang, F., Soto, C.G.: Older adults on electronic commerce: a literature review. Int. J. Bus. Adm. 9(3), 10-17 (2018)

32. Kim, M.J.: Does knowledge matter to seniors' usage of mobile devices? Focusing on motivation and attachment. Int. J. Contemp. Hosp. Manag. 28(8), 1702-1727 (2016)

33. Choudrie, J., Junior, C.O., McKenna, B., Richter, S.: Understanding and conceptualising the adoption, use and diffusion of mobile banking in older adults: a research agenda and conceptual framework. J. Bus. Res. 88, 449-465 (2018)

34. Almao, E.C., Golpayegani, F.: Are mobile apps usable and accessible for senior citizens in smart cities? In: Zhou, J., Salvendy, G. (eds.) HCII 2019. LNCS, vol. 11592, pp. 357-375. Springer, Cham (2019). https://doi.org/10.1007/978-3-030-22012-9_26

35. Mallenius, S., Rossi, M., Tuunainen, V.K.: Factors affecting the adoption and use of mobile devices and services by elderly people - results from a pilot study. 6th Annu. Glob. Mobil. Roundtable 31, 12 (2007)

36. Chen, A.N., Downey, J.P., Mcgaughey, R.E., Jin, K.: Seniors and information technology in China. Int. J. Hum. Comput. Interact. 32(2), 132-142 (2016)

37. Gatsou, C., Politis, A., Zevgolis, D.: Seniors' experiences with online banking. In: 2017 Federated Conference on Computer Science and Information Systems, vol. 11, pp. 623-627 (2017)

38. Ganor, N., Te'eni, D.: Designing interfaces for older users: effects of icon detail and semantic distance. AIS Trans. Hum.-Comput. Interact. 8(1), 22-38 (2016)

39. Seifert, A.: Mobile seniors: mobile use of the internet using smartphones or tablets by Swiss people over 65 years. Gerontechnology 1(1), 56-62 (2015)

40. Jayachandran, A.: E-banking or branch banking? Preference of senior citizens in Kerala. IUP J. Bank Manag. 18(2), 19-29 (2019)

41. Švecová, M., Odlerová, E.: Smartphone and mobile application usage among seniors in Slovakia. Eur. J. Sci. Theol. 14(6), 125-133 (2018)

42. Cullen, M., Kabanda, S.K.: The role of demographic and motivational factors on mobile commerce usage activities in South Africa. South African J. Inf. Manag. 20(1), 1-8 (2016)

43. Medhi, I., Gautama, S.N.N., Toyama, K.: A comparison of mobile money-transfer UIs for non-literate and semi-literate users. In: Proceedings of the SIGCHI Conference on Human Factors in Computing Systems, pp. 1741-1750 (2009)

44. Deb, M., Agrawal, A.: Factors impacting the adoption of m-banking: understanding brand India's potential for financial inclusion. J. Asia Bus. Stud. 11(1), 22-40 (2017)

45. Thakur, S.: The impact of information technology advancement in Indian banking sector. Int. J. Eng. Technol. Sci. Res. 5(1), 833-841 (2018)

46. Oseifuah, E.K.: Financial literacy and youth entrepreneurship in South Africa. African J. Econ. Manag. Stud. 1(2), 164-182 (2010)

47. Benamati, J.S., Serva, M.A.: Trust and distrust in online banking: their role in developing countries. Inf. Technol. Dev. 13(2), 161-175 (2007)

48. Dass, R., Pal, S.: Exploring the factors affecting the adoption of mobile financial services among the rural under-banked. In: European Conference on Information Systems (ECIS), p. $246(2011)$

49. Sharma, S.K., Govindaluri, S.M., Al-Muharrami, S., Tarhini, A.: A multi-analytical model for mobile banking adoption: a developing country perspective. Rev. Int. Bus. Strateg. 27(1), 133-148 (2017)

50. Nightingale, A.: A guide to systematic literature reviews. Surgery 27(9), 381-384 (2009)

51. Kitchenham, B.: Procedures for Performing Systematic Reviews, UK (2004)

52. Albashrawi, M., Motiwalla, L.: Understanding mobile banking usage: an integrative perspective. In: Proceedings of the 2017 ACM SIGMIS Conference on Computers and People Research, pp. 63-70 (2017) 
53. Ayaratne, M.G.S.D.N., Ryan, M., Cripps, H.: Mobile banking adoption by senior citizens in Perth. In: The Proceedings of 2nd Business Doctoral and Emerging Scholars Conference, p. 105 (2017)

54. Kargin, B., Basoglu, N., Daim, T.: Adoption factors of mobile services. Int. J. Inf. Syst. Serv. Sect. 1(1), 15-34 (2009)

55. Malaquias, R.F., Hwang, Y.: An empirical study on trust in mobile banking: a developing country perspective. Comput. Hum. Behav. 54, 453-461 (2016) 